\title{
Oxidative Status of the Myocardium in Response to Different Intensities of Physical Training
}

\author{
L. F. GUERREIRO ${ }^{1,2}$, A. M. ROCHA ${ }^{1,2}$, C. N. MARTINS ${ }^{1,2}$, J. P. RIBEIRO ${ }^{1,2}$, C. WALLY ${ }^{1,2}$, \\ D. L. STRIEDER ${ }^{1}$, C. G. CARISSIMI ${ }^{1}$, M. G. OLIVEIRA ${ }^{1}$, A. A. PEREIRA ${ }^{1}$, H. S. BIONDI ${ }^{1}$, \\ J. M. MONSERRAT ${ }^{1,2}$, C. A. N. GONÇALVES ${ }^{1,2}$ \\ ${ }^{1}$ Biological Sciences Institute, Federal University of Rio Grande - FURG, Rio Grande, RS, Brazil, \\ ${ }^{2}$ Postgraduate Program in Physiological Sciences - Comparative Animal Physiology, Federal \\ University of Rio Grande - FURG, Rio Grande, RS, Brazil
}

Received September 7, 2015

Accepted February 5, 2016

On-line July 15, 2016

\section{Summary}

The intensity of exercise determines the metabolic pathway and the energetic substrate that is spent. Our study sought to identify the effects of different intensities of swimming on myocardial oxidative status and the blood lipid profile. Eighty Wistar rats (male and female) submitted to different intensities of a swimming regimen (low, LS; moderate, MS; or high, HS) for 16 weeks. Samples of blood and myocardium from the left ventricle were collected to determine lipid profiles and oxidative status. Reactive oxygen species (ROS) and antioxidant capacity against peroxyl radicals (ACAP), lipid profiles and lipid peroxidation was analyzed. ROS levels and ACAP were higher in male rats than in female rats overall $(p<0.05)$. However, ACAP in the myocardium was significantly elevated in LS female rats compared to the MS and HS female rats, which had a significantly lower ACAP compared to all other groups. LS and MS training in both sexes and HS training (in females) led to significant decreases in the heart's lipid peroxidation. Amelioration of the lipid profile and reduction in oxidative damage contributed to a physiological state that benefits cardiovascular function in exercised animals. The results show that low and moderate intensity exercise promotes beneficial adaptations.

\section{Key words}

Cardiovascular • Exercise • Lipid profile • Swimming intensity • Oxidative stress

\section{Corresponding author}

C. A. N. Gonçalves, Biological Sciences Institute, Federal University of Rio Grande - FURG, Campus Carreiros, Avenida Itália Km 8, CEP 96.203-900, Rio Grande, RS, Brasil. Fax: +55 53 32336848. E-mail: camorimgon@gmail.com

\section{Introduction}

Exercise training has been shown to improve cardiovascular capacity and is associated with lower resting and submaximal heart rates, increased ventricular weight, and an improved lipid profile. It also increases exercise capacity and skeletal muscle strength (Thompson 2003, Trejo-Gutierrez and Fletcher 2007, Sugawara et al. 2012, Perrino et al. 2011). Exercise training represents one of the most severe, yet physiological, stresses to the cardiovascular system and determines which metabolic substrates are used (Perrino et al. 2011).

The intensity of exercise influences the metabolic pathway and the substrate spent as a source of energy, affecting the levels of energy stores and the lipid profile (Hernandez-Torres et al. 2009). Despite numerous investigations that emphasize the benefits of exercise training on the blood lipid profile, some uncertainty remains regarding the intensity of exercise that is needed to induce this and whether an optimum exercise intensity can be determined (Duncan et al. 2005, Ensign et al. 2002). Physiological adaptations to exercise are dependent on program length and session duration, 
frequency, and intensity. These factors make the prescription of physical exercise, which is intended to simulate situations similar to those applied to humans in experimental models, more complex (Araujo et al. 2012). The transposition of experimental data and physical training protocols to experimental physiology frequently becomes inadequate, leading to misunderstood data before publishing (Booth et al. 2010). Studies concerning the determination of aerobic and anaerobic metabolism have been developed, with the intent of improving the prescription of physical training in rats (Pilis et al. 1993, Gobatto et al. 2001, Carvalho et al. 2005, Manchado et al. 2006, Contarteze et al. 2008). The control of exercise intensity can be based on the production, accumulation, and removal of lactate in the blood stream. The anaerobic threshold (AT) is defined as the workload at which the blood lactate starts to accumulate excessively during progressive exercises. During physical exercise, the AT indicates the workload equivalent of the maximal lactate steady state (MLSS), which represents the highest concentrations of lactate in a determined load of work, which can be maintained over time (Manchado et al. 2006, Araujo et al. 2012, Ferreira et al. 2007, Gobatto et al. 2001). The MLSS intensity in rats can be identified during continuous exercise, considering an exercise intensity equivalent to a concentration of $4 \mathrm{mmol} / \mathrm{l}^{-1}$ of lactate in humans (Benek et al. 2011). The lactate concentrations at MLSS in rats have been studied (Carvalho et al. 2005, Gobatto et al. 2001, Manchado et al. 2006). During high-intensity physical activity, lactate blood levels higher than MLSS indicate that anaerobic metabolism predominates over aerobic (Manchado et al. 2006, Gobatto et al. 2001).

Some studies have shown that the cardiovascular adaptations of females differ from those of males; this includes the responses of morphological and physiological systems after exercise (Lindqvist et al. 2012, Aune et al. 2009, Dalen et al. 2010). These differences may stem from existing distinctions between males and females in types of muscle fuel stores, fuel utilization during exercise, and hormonal makeup (Steffensen et al. 2002). Following this line of logic, we hypothesized that exercise training at different intensities promotes distinct changes in the cardiovascular system and that these changes are dependent on gender.

Regular physical exercise has been shown to improve the lipid profile and increase mean life span (Kraus et al. 2002, Radak et al. 2008). An inevitable consequence of exercise is that the increased oxygen consumption induced by exercise creates favorable conditions for increased generation of reactive oxygen/nitrogen species (RONS), an increased cardiac oxidative metabolic rate, leading to alterations in the cellular redox status and activating pathways of cell death (Ascensão et al. 2007).

In addition to RONS generation, the products of lipid peroxidation may cause alterations in the cell membrane, as well as damage to proteins and DNA (Radak et al. 1999). Together, lipid oxidation and inflammation of vessels play a fundamental role in the development of atherosclerosis (Wang et al. 2006). Exercise training in diverse experimental protocols is capable of augmenting peroxidation in humans and murine models (Groussard et al. 2003, Chirico et al. 2012). Oxidative conditions in the heart have been associated with cardiovascular diseases, mainly myocardial infarction (Shiomi et al. 2004). Scientific evidence indicates that physical exercise may improve antioxidant capacity and reduce damage to cardiac tissue caused by oxidative stress (Pinho et al. 2012, Powers et al. 2008). During and after exercise, various mechanisms are activated in different organs and systems to maintain or restore cell homeostasis and exercise intensity can affect the cardiovascular system. Few studies have focused on the chronic effects of aerobic and anaerobic exercise on oxidative status and lipid profile. The aim of this study was to investigate the effects of different intensities of exercise training (low, moderate, and high) on the oxidative status of the myocardium and lipid profile in male and female rats.

\section{Methods}

\section{Experimental model}

Sixty-day-old Wistar rats (Rattus norvegicus), forty males and forty females, were obtained from the Central Animal House of the Federal University of Rio Grande (FURG), Brazil. Mean weight was $312 \pm 10 \mathrm{~g}$ (male rats) and $214 \pm 4 \mathrm{~g}$ (female rats). Animals were housed in plastic cages (five animals per cage) and maintained at $24^{\circ} \mathrm{C} \pm 1{ }^{\circ} \mathrm{C}$ in a 12-hour light-dark cycle, and they received commercial rodent food and water $a d$ libitum. Rats were weighed once a week, and food consumption was monitored daily by weighing leftover food. Training sessions were performed during the dark cycle. The experiments were performed according to Guide for the Care and Use of Laboratory Animals and Use of Vertebrate Animals in Research and Training and 
official Brazilian governmental guidelines, in compliance with the Federation of Brazilian Societies of Experimental Biology. The study was approved by the Ethics Committee on Animal Use, Federal University of Rio Grande (CEUA-FURG).

\section{Training protocol}

Training protocol followed Guerreiro et al. (2015). Rats were randomly distributed into four groups $(\mathrm{n}=10)$ : sedentary control (SC); low-intensity swimming training (LS) and moderate-intensity swimming training (MS), both of which induced aerobic metabolism; and high-intensity swimming training (HS), which induced anaerobic metabolism. The untrained SC group was placed in the swimming apparatus for 1 min one time per day, 5 days per week, to mimic the water stress associated with the experimental protocol and handling.

The continuous exercise swimming system of low and moderate intensity consisted of a rectangular tank (90 cm width $\times 100 \mathrm{~cm}$ length $\times 80 \mathrm{~cm}$ height) filled with water up to $50 \mathrm{~cm}$. Ten PVC pipes of $20 \mathrm{~cm}$ width and $50 \mathrm{~cm}$ length were placed inside the tanks. The water temperature was kept close to $32^{\circ} \mathrm{C}$. Therefore, the animals were able to realize the exercise individually, each individual in a different PVC pipe. The highintensity intermittent swimming system was realized using a pulley system coupled to a cylinder of $60 \mathrm{~cm}$ width with 10 PVC pipes. The cylinder was immersed in the swimming tank described above for 15 seconds, forcing the animals to swim vigorously. Then the cylinder was lifted by the pulley system, allowing the animals to recover for 15 seconds out of the water (Guerreiro et al. 2015).

Rats performed a training program one time per day, 5 days per week, during a 16-week period divided into two periods. An initial period of acclimation was 8 weeks long; during this period, the training load and duration of swimming progressively increased (20 $\mathrm{min}$ in the first week, up to $60 \mathrm{~min}$ at the eighth week; Fig. 1). The second training period was characterized by the maintenance of higher loads of swimming training and duration of exercise (60 min and a workload of $5 \%$ [MS] or $15 \%$ [HS]) for 8 more weeks. The load was adjusted weekly according to body weight (Table 1). The protocols were as follows:

The LS experimental group performed lowintensity aerobic swimming without overload, during $60 \mathrm{~min}, 5$ times a week, for 8 weeks. This methodology intended to simulate an exercise in which the intensity is not controlled by overload. This protocol aimed to simulate a common physical activity that is performed by humans, such as walking or jogging at controlled frequency and duration. The MS experimental group engaged in moderate swimming for $60 \mathrm{~min}$, 5 times a day, with progressive overload during accli-matization periods (increased from $1 \%$ to $5 \%$ of body weight). This overload was created by attaching pieces of lead to the back of the animal, and was equivalent to the MLSS. The HS experimental group performed high-intensity intermittent anaerobic swimming during $60 \mathrm{~min}, 5$ times a week, for 16 weeks. Each 60-minute session consisted of alternate periods of vigorous swimming for 15 seconds, followed by a recovery resting period for 15 seconds, with overload increased from $8 \%$ to $15 \%$ of body weight equivalent at intensities above the MLSS (Fig. 1) (Guerreiro et al. 2015).

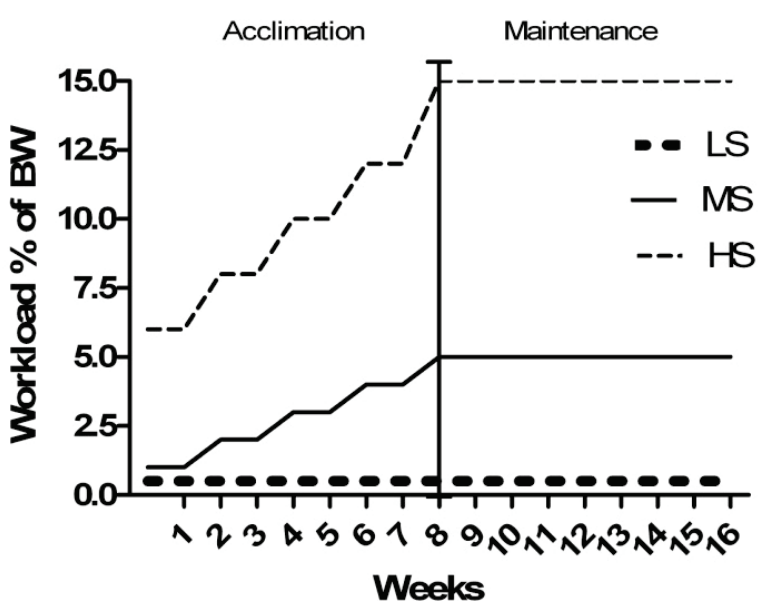

Fig. 1. Training program during a 16 -week period divide into two periods: Acclimation ( 8 weeks) and maintenance ( 8 weeks) LS: low-intensity swimming, without workload. MS: moderateintensity swimming with load equal to $5 \%$ of body weight. HS: high-intensity swimming with load equal to $15 \%$ of body weight.

\section{Determination of blood lactate levels}

The lactate levels were determined during the exercising procedure. The lactate was collected at three different time points. First, to determine the loads of swimming, a test of initial lactate was conducted. Second, another collection was made after 8 weeks of acclimation training. The third collection of lactate was made after 12 weeks of training. During the exercise, the rats were removed from the water at 10, 20, 30 and $40 \mathrm{~min}$ and dried, and blood samples $(25 \mu \mathrm{l})$ were collected by cutting off the tip of the tail (Voltarelli et al. 2002). Lactate concentrations were determined in $\mathrm{mmol} / \mathrm{l}$ with a lactate analyzer (Accutrend). 
Table 1. Body weight and food intake of groups submitted to different intensities of swimming training.

\begin{tabular}{lcccccccc}
\hline & \multicolumn{2}{c}{ SC } & \multicolumn{2}{c}{ LS } & \multicolumn{2}{c}{ MS } & \multicolumn{2}{c}{ HS } \\
\cline { 2 - 8 } & Female & Male & Female & Male & Female & Male & Female & Male \\
\hline BW initial (g) & $225 \pm 12$ & $320 \pm 18^{*}$ & $217 \pm 13$ & $313 \pm 24^{*}$ & $222 \pm 17$ & $295 \pm 33^{*}$ & $227 \pm 23$ & $295 \pm 25^{*}$ \\
BW (8 weeks) (g) & $250 \pm 16$ & $385 \pm 16^{\mathrm{a} *}$ & $238 \pm 14$ & $381 \pm 32^{\mathrm{a} *}$ & $243 \pm 15$ & $350 \pm 41^{\mathrm{b} *}$ & $244 \pm 22$ & $343 \pm 31^{\mathrm{b} *}$ \\
BW (12 weeks) (g) & $269 \pm 20^{\mathrm{a}}$ & $450 \pm 16^{\mathrm{a} *}$ & $257 \pm 16^{\mathrm{b}}$ & $447 \pm 35^{\mathrm{a} *}$ & $257 \pm 22^{\mathrm{b}}$ & $419 \pm 48^{\mathrm{b} *}$ & $256 \pm 26^{\mathrm{b}}$ & $396 \pm 46^{\mathrm{c} *}$ \\
BW end (g) & $285 \pm 22^{\mathrm{a}}$ & $467 \pm 23^{\mathrm{a} *}$ & $268 \pm 18^{\mathrm{b}}$ & $460 \pm 35^{\mathrm{ab} *}$ & $268 \pm 23^{\mathrm{b}}$ & $440 \pm 45^{\mathrm{b} *}$ & $271 \pm 24^{\mathrm{b}}$ & $403 \pm 43^{\mathrm{c} *}$ \\
Food intake (g/day) & $19.59 \pm 0.40^{\mathrm{a}}$ & $27.44 \pm 0.72^{\mathrm{a} *}$ & $19.01 \pm 0.90^{\mathrm{ab}}$ & $26.25 \pm 0.85^{\mathrm{a} *}$ & $18.35 \pm 0.35^{\mathrm{bc}}$ & $23.58 \pm 1.47^{\mathrm{b} *}$ & $17.61 \pm 0.88^{\mathrm{c}}$ & $22.55 \pm 1.43^{\mathrm{b} *}$ \\
\hline
\end{tabular}

BW initial: body weight before initiation of exercise training. BW (8 weeks): body weight after eight weeks of exercise training. BW (12 weeks): body after twelve weeks of exercise. BW end: body weight after the end of the experiment (16 weeks) Food intake: mean of food consumption through of the experiment. Treatments: SC (sedentary control); LS (low-intensity); MS (moderateintensity); HS (high-intensity). Data were expressed as mean \pm SD. Different letters mean significant differences between treatments and $(*)$ means statistical differences between sexes at the significant level of $5 \%$.

\section{Tissue samples}

At the end of the acclimation period of swimming training (eighth week), the rats were sedated and blood samples were collected from the retro-orbital sinus. Seventy-two hours after the end of the training period (16 weeks), the rats were euthanized by beheading. The period of 72 hours before euthanasia was chosen because it is known that some effects of physical exercise on the lipid profile and oxidative stress can last up to 48 hours (Hughes et al. 1990, Abernethy and Azarnoff 1990). Their blood was collected in tubes and centrifuged to obtain plasma for analyses of the blood lipid profiles. The hearts were rapidly removed by dissection, weighed, and stored at $-80{ }^{\circ} \mathrm{C}$.

\section{Lipid Profile}

Levels of total cholesterol (TC), triglycerides (TG), and high-density lipoprotein cholesterol (HDL-C) were determined by colorimetry kits (Labtest). Plasma samples were mixed and incubated with the specific reagent for $10 \mathrm{~min}$ at $37^{\circ} \mathrm{C}$, and the absorbance $(510,520$, and $505 \mathrm{~nm}$, respectively) was read by spectrophotometer. The difference between TC and HDL-C was recorded as the low-density lipoprotein cholesterol (LDL-C) concentration. All levels were expressed as mg/dl.

\section{Analysis of reactive oxygen species}

Left ventricle tissue (approximately $100 \mathrm{mg}$ ) was homogenized in potassium chloride $(\mathrm{KCl}) 1.15 \%$ and phenylmethanesulfonyl fluoride (PMSF) (10 mmol/l) for 30 seconds, followed by $3000 \mathrm{~g}$ centrifugation for $10 \mathrm{~min}$ at $4{ }^{\circ} \mathrm{C}$ (Jacob et al. 2006). Total protein content was determined by colorimetric assay (Biuret method, Labtest) in triplicate using a microplate reader (BioTek LX 800) at
$550 \mathrm{~nm}$. Each sample was diluted to $2 \mathrm{mg}$ of protein $/ \mathrm{ml}$ in homogenization buffer. Reactive oxygen species (ROS) were assayed by $2^{\prime}, 7^{\prime}$-dichlorodihydrofluorescein diacetate $\left(\mathrm{H}_{2} \mathrm{DCF}-\mathrm{DA}\right)$ indicator (Invitrogen). The non-fluorescent compound $\mathrm{H}_{2} \mathrm{DCF}-\mathrm{DA}$ is first de-acetylated and then oxidized by ROS to the fluorescent compound dichlorofluorescein (DCF), which is detected at 488 and $525 \mathrm{~nm}$ for excitation and emission, respectively, into a fluorescence microplate reader (Victor 2, Perkin Elmer). Readings were performed every 5 min during a 30-minute period. Fluorescence data were adjusted to a second-order polynomial function and integrated to calculate the area that expressed ROS concentration (Amado et al. 2009).

\section{Antioxidant capacity against peroxyl radicals}

Total antioxidant capacity against peroxyl radicals (ACAP) is a method described by Amado et al. (2009) that determines the tissue's capacity to confront peroxyl radicals. According to these authors, peroxyl radicals are produced by thermal decomposition of the generator 2,2'azobis(2-methylpropionamidine) dihydrochloride (ABAP) $4 \mathrm{mM}$ (Aldrich) at $35^{\circ} \mathrm{C}$. The assays were run at $37^{\circ} \mathrm{C}$ because this temperature is indicated for mammalian models. This methodology is conducted as an ROS assay, but in this case DCF production is increased by ABAPperoxyl radical generation. ROS concentration in the presence of ABAP is also expressed by the area calculated from the second-order polynomial function, resulting from the adjustment of fluorescence units during the measurement time. Total antioxidant competence was expressed as relative area calculated by the rate of the difference between ROS area, with ABAP and without ABAP, divided by ROS area without ABAP, as a standardization factor of ROS background production. 


\section{Lipid peroxidation}

Myocardium samples $(50 \mathrm{mg}$ ) were homogenized with $\mathrm{KCl} 1.15 \%$ plus $35 \mathrm{mM}$ of butylated hydroxytoluene according to Oakes and Van Der Kraak (2003). This method, previously described, involves the reaction of malondialdehyde (MDA), a degradation product of lipid peroxidation (LPO), with 2-thiobarbituric acid (TBA) under conditions of high temperature and acidity to generate a fluorescent adduct that was measured by spectrofluorometry (Victor 2, Perkin Elmer). After excitation at $515 \mathrm{~nm}$ and emission of $553 \mathrm{~nm}$, the concentration of TBA-reacting substances (TBARS) was calculated and expressed in $\mathrm{nmol} / \mathrm{mg}$ of proteins.

\section{Statistical analysis}

Data were expressed as means \pm standard deviations (SDs) and analyzed by one-way analysis of variance (ANOVA) or Kruskal-Wallis ANOVA when the assumption of normality or homoscedasticity was not reached, followed by posteriori Tukey Highly Significant Difference test. Sex differences were compared by an independent Student's T-test. Statistical significance was set at $p$-values $\leq 0.05$.

\section{Results}

Lactate levels during swimming training behaved according to expectations for each workload intensity. LS training did not change the rats' lactate levels versus the SC group, confirming the low workload. Lactate rose significantly $(\mathrm{p}<0.05)$ in HS rats (female rats: $9.88 \pm 1.77 \mathrm{mmol}$; male rats: $9.27 \pm 3.4 \mathrm{mmol}$ ) and $\mathrm{MS}$ rats (female rats: $5.26 \pm 0.56 \mathrm{mmol}$; male rats: $5.68 \pm 0.84 \mathrm{mmol}$ ) compared to SC rats (female rats: $2.4 \pm 0.3 \mathrm{mmol}$; male rats: $3.04 \pm 0.2 \mathrm{mmol}$ ) (Fig. 2), demonstrating that both loads resulted in high and moderate efforts, respectively. Gender was not statistically related to changes in lactate levels $(\mathrm{p}>0.05)$.

Male rats had significantly $(p<0.05)$ higher weights than female rats throughout the experiment. A significant reduction in body weight of male rats in the MS and HS groups (-11\% and $-12 \%$, respectively) was observed at the end of the adaptation period $(\mathrm{p}<0.05$; Table 1). In female rats, body weight reduction starts at 12th week of the experiment (Table 1). At that time, male rats in the MS (-10\%) and HS (-16\%) groups and female rats in the LS (-5\%), MS (-6\%), and HS (-6\%) groups presented a significant $(\mathrm{p}<0.05)$ lower weight than the SC group rats (Table 1).

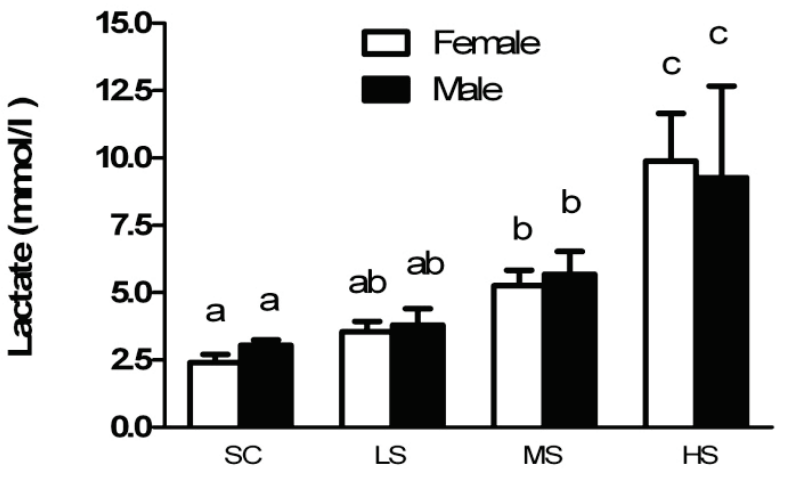

Fig. 2. Lactate Test in acclimation period (8 weeks). SC: sedentary control. LS: low-intensity swimming, without workload. MS: moderate-intensity swimming. HS: high-intensity swimming. Data are expressed as mean \pm SDs $(\mathrm{mg} / \mathrm{dl})$. Different letters indicate significant differences between groups at significance level of $5 \%$.

Food intake might explain the observed reductions in body weight. Rats of both sexes in the MS and HS groups consumed a significantly smaller quantity of food (in grams) than the SC and LS rats (Table 1). Following the tendency to observe the highest body weight in male rats, food intake was also significantly higher in male rats than in female rats (Table 1).

After the adaptation period, female rats did not show any change in lipid profile between treatments (Fig. 3), while male rats showed a significant reduction ( $<<0.05$, MS $-28 \%$ and HS $-26 \%$ ) in TC (Fig. 3A). LDL-C and HDL-C also decreased in male rats in the HS group $(\mathrm{p}<0.05)$. TG levels in male rats did not differ significantly between intensities, and they were higher than in female rats during this period ( $p<0.05$, Fig. 3B).

By the end of the training period, female rats (LS: $-27 \%$, MS: $-50 \%$, HS: $-52 \%$ ) and male rats (MS: $-28 \%$ and HS: $-27 \%$ ) presented a significantly $(\mathrm{p}<0.05)$ lower TC content compared to SC rats (Fig. 4A). Also, LDL-C showed the same reduction pattern (female rats LS: $-44 \%$; MS: $-60 \%$, HS: $-74 \%$; male rats MS: $-48 \%$ and HS: $-29 \%$ ) compared to the respective SC group (Fig. 4D). Swimming training, regardless of intensity, decreased TG in male rats (LS: $-28 \%$, MS: $-28 \%$, HS: $-27 \%$ ) compared to SC. Male rats continued to present higher levels of TG than female rats in the SC and MS groups ( $p<0.05$, Fig. 4B). There were no changes in the TG and HDL-C levels in female rats. HDL-C in male rats increased in the MS group and decreased in the HS group relative to $\mathrm{SC}$ ( $\mathrm{p}<0.05$, Fig. $4 \mathrm{C}$ ). Female rats showed higher levels of HDL-C in SC, LS, and HS groups compared to the respective groups of male rats. 
(A)

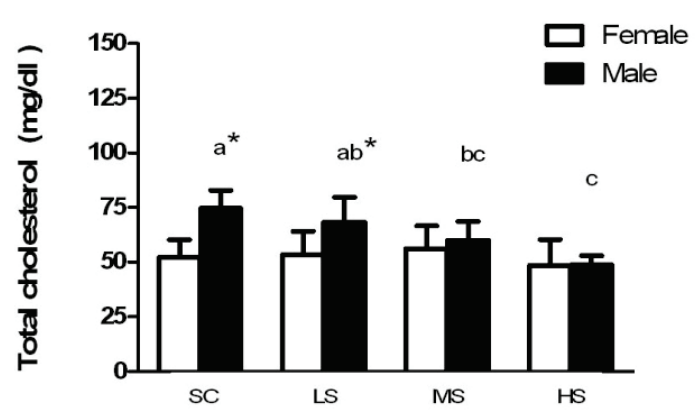

(C)

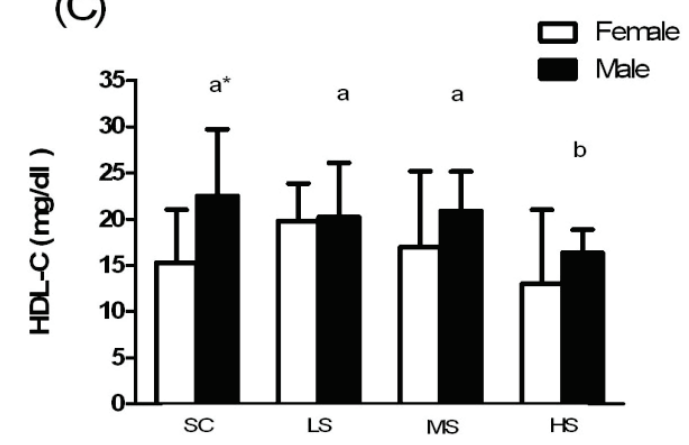

(B)

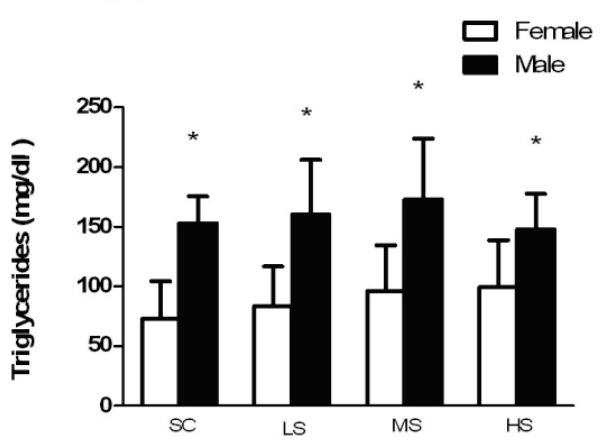

(D)

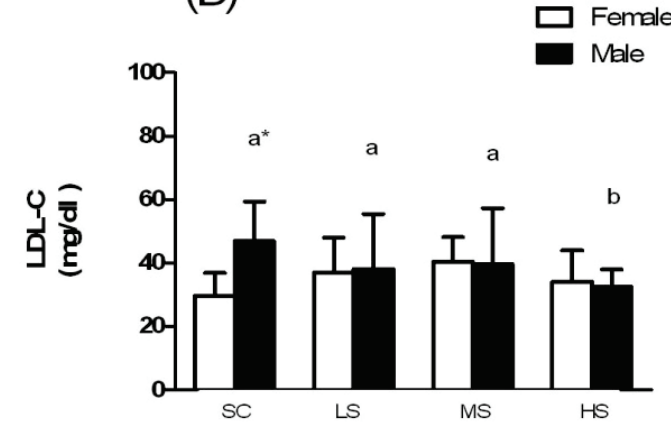

Fig. 3. Lipid profile at the end of the acclimation period ( 8 weeks) of Rattus norvegicus submitted to different intensities of swimming training. (A) Total cholesterol contents; (B) Triglyceride levels; (C) HDL-C - High density lipoprotein cholesterol contents; (D) LDL-C - Low density lipoprotein cholesterol contents. Data are expressed as means $\pm \mathrm{SDs}$ ( $\mathrm{mg} / \mathrm{dl})$; white bars, female rats; black bars, male rats. Different letters indicate significant differences between groups; *statistically significant differences between sexes at the $5 \%$ significance level.

(A)

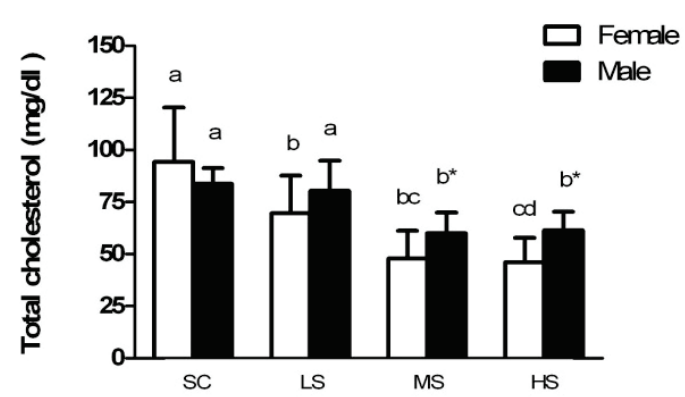

(C)

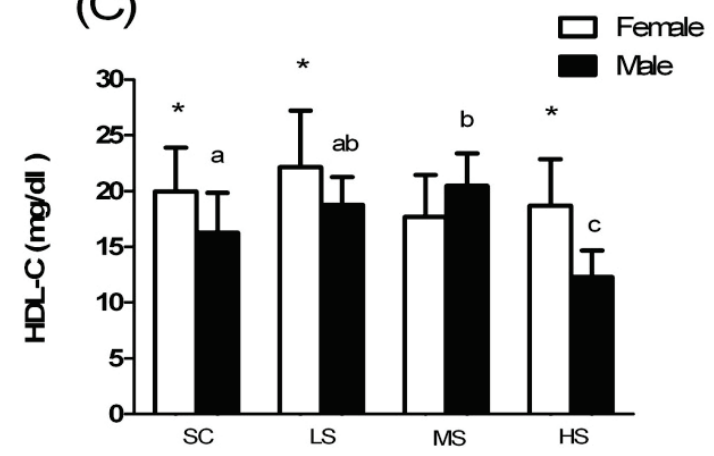

(B)

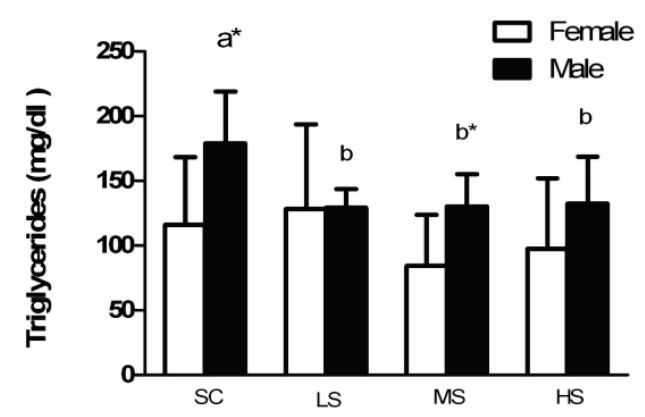

(D)

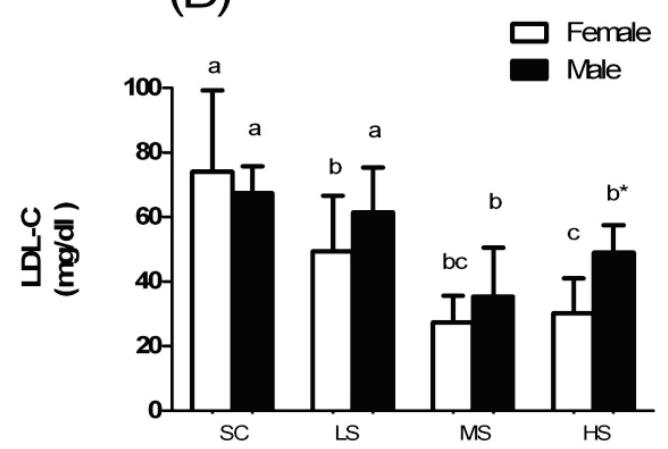

Fig. 4. Lipid profile at the end of the experiment (16 weeks) of Rattus norvegicus submitted to different intensities of swimming training. (A) Total cholesterol contents; (B) Triglycerides levels; (C) HDL-C - High density lipoprotein cholesterol contents; (D) LDL-C - Low density lipoprotein cholesterol contents. Data are expressed as means \pm SDs (mg/dl); white bars, female rats; black bars, male rats. Different letters indicate significant differences between groups; *statistically significant differences between sexes at the $5 \%$ significance level. 

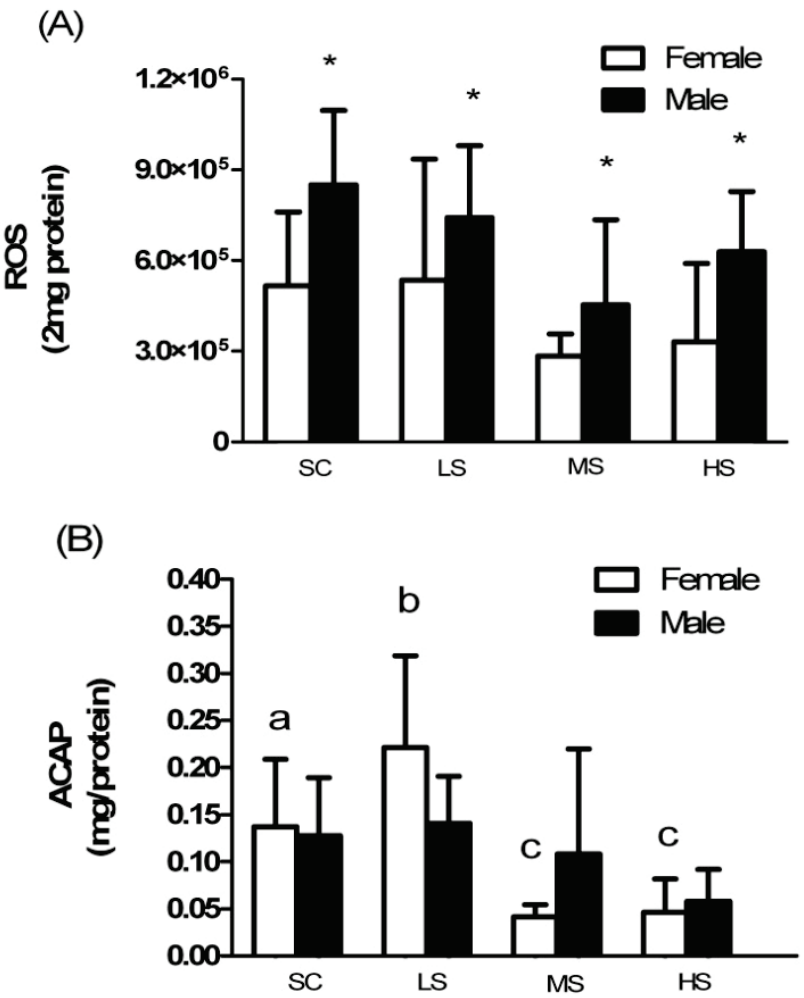

Fig. 5. (A) Reactive oxygen species (ROS) in the myocardium; (B) ACAP in the myocardium after different intensities of swimming training. Data are expressed as means \pm SDs (fluorescence area); white bars, female rats; black bars, male rats; *statistically significant differences between sexes at the $5 \%$ significance level.

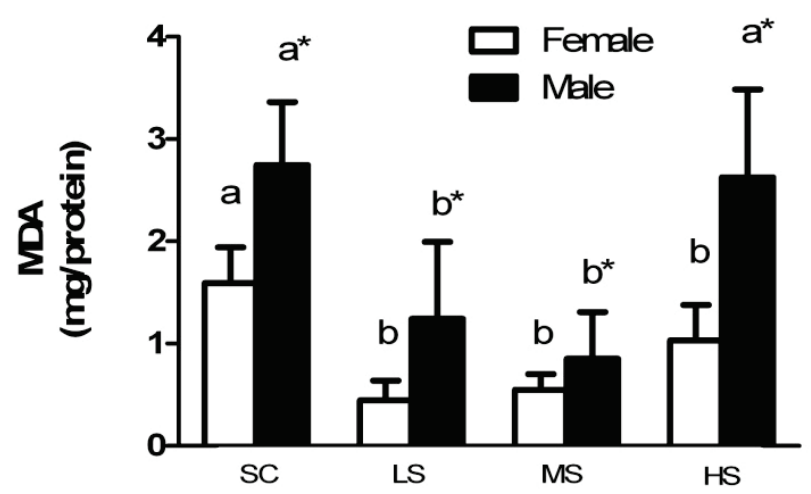

Fig. 6. Lipid peroxidation determined by malondialdehyde levels (MDA) in the myocardium of Rattus norvegicus submitted to different intensities of swimming training. Data are expressed as means \pm SDs (mg/protein); white bars, female rats; black bars, male rats. Different letters indicate significant differences between groups; *statistically significant differences between sexes at the significant level of $5 \%$.

Cardiac ROS concentration at 72 hours after the end of the experiment did not show any difference between training and $\mathrm{SC}$ groups $(\mathrm{p}>0.05)$. However, sexrelated differences were observed, with male rats presenting higher ROS than female rats $(p<0.05$, Fig. 5A). Myocardium ACAP was significantly increased only in LS female rats compared to all others (Fig. 5B). The MS and HS female rats showed a significant reduction in ACAP compared to all groups (Fig. 5B). ACAP levels in male rats were not altered by swimming training. LPO in myocardium was significantly diminished in female rats (LS, MS, and HS groups) and in male rats (LS and MS groups only) compared to SC rats $(p<0.05$, Fig. 6). Male rats had higher LPO than female rats ( $p<0.05$, Fig. 6 ).

\section{Discussion}

Studies in exercise physiology need to acclimate animals to the intended loads and activities to be performed. Araujo et al. (2013), who studied rats using a monotonous training regimen without progressive habituation to load/time volume, observed a reduction in the amount of training (less time spent engaged in physical activity), increased muscle damage and reduced anaerobic capacity. To guarantee the execution of an exercise program completely, it is important to progressively acclimate subjects to load/time volume, although this is commonly missing from studies of experimental exercise physiology (Booth et al. 2010, de Araujo et al. 2013). To this purpose, was included here an acclimation period, with gradual increment of time and load until reach $60 \mathrm{~min}$ of exercise 5 times per week and to achieve a maximum load at $5 \%$ for MS and $15 \%$ for HS. Such protocol was effective for inducing aerobic and anaerobic metabolism, as observed by the expected blood lactate values, similar to those already reported (Voltarelli et al. 2002). Chronic exercise can have negative effect on mitochondrial glycerol phosphate dehydrogenase, reducing lactate generation (CasimiroLopes et al. 2012). In our experiment, it was not seen, because the physical training loads are incremental over time, allowing an increased effort during swimming keeping lactate levels adequate for the intended intensity.

The relationship between swimming intensity and reduced body weight detected herein could be associated with the reduction in food intake. Fatty acid oxidation increases in response to prolonged low- and moderate-intensity exercise for the purpose of skeletal muscle maintenance (Trejo-Gutierrez and Fletcher 2007, Ensign et al. 2002). Our swimming protocol could be promoting fatty acid oxidation, not exclusively in LS or 
MS, but also in HS training. This overall weight reduction is one of the changes stimulated by exercise that may ameliorate cardiovascular risk factors (Durstine and Haskell 1994). Herein, males ate more food than females but lost weight faster; a study of obesity (Ropelle et al. 2006) observed that physical exercise suppressed hyperphagia, which was to linked to central action of insulin and leptin in the hypothalamus of mice. Our swimming protocols at all intensities and in both genders could be promoting weight loss by: (1) increasing the amount of fat burned and/or (2) changing the central mechanism that signals satiety.

In both sexes, exercise led to reduced $\mathrm{TC}$ and LDL-C concentrations compared to SC animals. In addition, all swimming intensities promoted a significant reduction in TG in male rats. These findings support that exercise induces fatty acid lipolysis, resulting in the improved blood lipid profile (Tunstall et al. 2002). However, HDL-C in female rats was not altered by any swimming training, although its levels were decreased in HS male rats. Such a decrease in HDL-C in male rats could also be a consequence of exacerbated fatty acid oxidation, including cholesterol, promoted by the highintensity protocol.

The increase in HDL-C seen in MS male rats could be mediated by some key enzymes, such as lecithin cholesterol acyltransferase and lipoprotein lipase (Hamilton et al. 1998, Wittrup et al. 1997), as has already been verified in Sprague-Dawley rats exercised with voluntary running wheels. This augmented HDL-C profile imparts a benefit to cardiovascular health and could be considered a good physiological adaptation to exercise that is achieved with moderate-intensity activity. LS or HS training may be too mild or too intense, respectively, to promote this benefit. Female rats, for instance, already had a higher HDL-C than male rats, so exercise could not result in higher values.

An interesting finding of this work was that the HS training protocol was able to reduce TC, TG, and LDL-C. Another study, which examined 22-month-old rats submitted to swimming training for $60 \mathrm{~min} /$ day for 4 months in a high-intensity ( $5 \%$ load) situation, did not observe significant changes in lipid profile (Ravi et al. 2006). The reason for this difference could be that $5 \%$ for older rats may be too intense to promote an alteration in lipid profiles. Another study, in which rats utilized a resistance exercise protocol for 3 days a week for 8 weeks, did not observe any reduction in lipid profile (Yang et al. 2006).
Our results suggest that low-intensity (in female rats only), moderate-intensity, and high-intensity swimming training may increase fatty acid oxidation. These findings point to the possibility that high-intensity training could be beneficial in elevating fatty acid oxidation and reducing $\mathrm{TC}$, LDL-C, and $\mathrm{TG}$, as was commonly observed in LS and MS rats.

The varying patterns of body weight reduction and lipid profile amelioration observed in male rats and female rats could be caused by different adaptive enzyme responses and/or influenced by sex hormones. Some authors (Campbell and Febbraio 2001), who studied the effect of ovarian hormones on mitochondrial enzyme activity in the fat oxidation of female rats, observed that ovarian sex steroids participated in the control of the maximal activity of several key enzymes of lipid oxidation.

We observed that even low-intensity swimming might reduce female rats' body weight, food intake, and TC and LDL-C levels, while these benefits were observed only in MS and HS male rats. This could be a result of a dimorphic interaction between exercise and sex hormones. In contrast, neither TG nor HDL-C changed in trained female rats, regardless of exercise intensity, attesting to the hypothesis that exercise does not have a similar influence on lipid metabolism in the different genders. Perhaps as a means of hormonal protection, female rats tend to have a higher HDL-C concentration than male rats. Another sex difference observed was the lapse in time response to exercise: whereas male rats presented significant differences after the 8-week adaptation period, female rats did not show differences until after the 12-week training period. The present protocol was effective in promoting reductions in body weight and blood lipids, although these reductions were the slowest in female rats on the low-intensity regimen. In spite of these differences, both sexes benefited from the swimming protocols.

An inevitable consequence of the increased oxygen consumption induced by exercise is a favorable condition for increased generation of RONS and, apparently, an increase in oxidative stress (Powers et al. 2008). Previously, Storey (1996) showed that ascorbic free radical signals were increased in the rat heart after several consecutive days of exercise. Using DCF, another study (Kumar et al. 1992) demonstrated that the ROS production rate was significantly increased in the muscle of rats that were exhaustively exercised. Ramos et al. (2013) presented data that the oxidative stress biomarkers 
measured in the plasma immediately after a single bout of swimming exercise were generated primarily in the liver, not in muscle. Our data showed that long-term training (16 weeks) via a low-, moderate-, or high-intensity swimming protocol did not alter basal ROS concentration in myocardium at 72 hours after the last training session in resting rats. But do not rule out the hypothesis that there may be oxidative modifications in other organs in response to physical training. Several works have verified elevation of ROS following exercise, and this is probably a result of very close analysis of an exercise session. In this situation, higher ROS levels could reflect an acute response to exercise, rather than a chronic effect of it. In addition, overtraining could be responsible for the increase in ROS, indicating a maladaptive effect of exhaustive exercise. Males showed significantly greater production of ROS than females. Previous studies demonstrate that estrogen confer favorable effects on cardiovascular system, diminishing generation of reactive species of oxygen elicited by regulation of ROSgenerating enzymes or by promoting ROS eliminating (Colom et al. 2007, Arias-Loza et al. 2013). Protection of females against ROS can be explained by sexual dimorphism in the transcriptional levels of genes associated with fatty acid metabolism, pyruvate dehydrogenase complex, and oxidative phosphorylation in hearts, highering resistance to oxidative stress (Vijay et al. 2015).

Our data also point to a beneficial effect of exercise in myocardial reduction of LPO in female rats (all swimming groups) and male rats (LS and MS groups). These results agree with other studies that observed a LPO reduction in skeletal muscle of mice exercised with a low-intensity treadmill (Kaczor et al. 2007). Another study (Ravi et al. 2006) observed that swimming training (low, moderate, and high) decreases myocardial MDA content compared to sedentary controls. We also found significantly lower levels of MDA in females than in males, which is in agreement with previous studies (Bloomer and Fisher-Wellman 2008, Goldfarb et al. 2007). In contrast, other research found increased MDA in the hearts of rats submitted to chronic ( 8 weeks) and acute exhaustive treadmill exercise (Liu et al. 2000), but this was probably an effect related to overtraining. However, the apparently unexpected uncoupled response of LPO, which diminished in all swimming groups, and ACAP, which rose only in LS female rats, could be explained by the differing influences of exercise intensities on the antioxidant systems. This was already detected in one study; different combinations of exercise intensity (low, moderate and high) and duration (30,60, and $90 \mathrm{~min} /$ day) of swimming protocols were observed, and they produced different regulations of the antioxidant enzymes superoxide dismutase, catalase, and glutathione peroxidase (GPX) in the left ventricle of trained rats (Powers et al. 2008). In Sprague-Dawley rats submitted to endurance and exhaustive swimming training, during exercise of increased intensity, glutathione and glutathione reductase enzyme activity decreased, whereas an increase was observed in GPX activity (Aydin et al. 2007).

The adaptive responses of the antioxidant system, and the expression of the various indirect markers of oxidative tissue damage, would be specific to either the type of tissue or the different defense mechanism affected (Ascensão et al. 2007). It would explain why only LS showed an elevated antioxidant capacity against peroxyls, indicating an exercise intensity-specific response. However, MS and HS rats did not show increases in antioxidant capacity, which does not exclude the possibility that other defense systems are being affected by these workloads. Radicals may seem beneficial, as they act as signals to enhance defenses, rather than as deleterious, as they are when cells are exposed to high levels of them (Jones 2006, Powers et al. 2008). Following this point of view, the ROS generation that is habitually observed during exercise could be a sign of an adaptive antioxidant response. Our swimming training program caused a reduction in lipid peroxidation, no alteration in ROS during rest, and, under a lowintensity regimen, enhanced antioxidant systems.

In humans, genetic endowment and nutritional habits can lead to increased lipid profile, oxidative stress, inflammatory process, hypertension, myocardial infarction, atherosclerosis, collectively known the cardiovascular diseases (CVDs), contribute greatly to the mortality, morbidity (Buttar et al. 2005). This study, in rats we observed that intensity of exercise can modulate blood lipid profile and myocardial oxidative status, indicated that all levels of intensity of exercise training promoted amelioration of lipid profiles, especially reducing TC and LDL-C, which could improve health and diminish the risk of cardiovascular disease in both sexes. This study suggested that female rats showed improvement in lipid profiles following low-intensity exercise, while male rats required moderate- and highintensity exercise to achieve this same benefit. Male rats and female rats responded similarly to the exercise 
intensities, but some sex-specific patterns were distinguished, as male rats responded earlier to exercise, whereas female rats responded later but after lowerintensity exercise than male rats. Over a chronic (16-week) training period, the exercise intensities that helped females were LS and MS. In male rats, MS was the best intensity for cardiac adaptation, considering adaptation patterns observed for TC, LDL-C, antioxidant capacity, and LPO.

Future investigations in this model will unveil novel molecular, cellular, oxidative stress and integrative mechanisms of adaptation to different intensities of swimming training in comparing genders. Understanding the mechanisms of training-induced amelioration of cardiovascular function may help identify molecular targets for the beneficial adaptation of the cardiovascular system induced by exercise.

\section{Conflict of Interest}

There is no conflict of interest.

\section{Acknowledgements}

The authors would like to acknowledge CAPES/CNPq for financial support and the fellowship of L. F. Guerreiro. J. M. Monserrat receives a scientific productivity fellowship from CNPq. This work received financial support from the Brazilian Federal Agency for Support and Valuation of Graduate Education (Coordenação de Aperfeiçoamento de Pessoal de Nível Superior, CAPES).

\section{References}

ABERNETHY DR, AZARNOFF DL: Pharmacokinetic investigations in elderly patients. Clinical and ethical considerations. Clin Pharmacokinet 19: 89-93, 1990.

AMADO LL, GARCIA ML, RAMOS PB, FREITAS RF, ZAFALON B, FERREIRA JL, YUNES JS, MONSERRAT JM: A method to measure total antioxidant capacity against peroxyl radicals in aquatic organism: application to evaluate microcystins toxicity. Sci Total Environ 407: 2115-2123, 2009.

ARAUJO GG, PAPOTI M, Dos REIS IG, DE MELLO MA, GOBATTO CA: Physiological responses during linear periodized training in rats. Eur J Appl Physiol 112: 839-852, 2012.

ARAUJO GG, PAPOTI M, MANCHADO-GOBATTO FDE B, DE MELLO MA, GOBATTO CA: Monitoring chronic physical stress using biomarkers, performance protocols and mathematical functions to identify physiological adaptations in rats. Lab Anim 47: 36-42, 2013.

ARIAS-LOZA PA, MUEHLFEDLDER M, PELZER T: Estrogen and estrogen receptors in cardiovascular oxidative stress. Pflugers Arch 465: 739-746, 2013.

ASCENSÃO A, FERREIRA R, MAGALHARES J: Exercise induced cardioprotection biochemical, morphological and functional evidence in whole tissue and isolated mitochondria. Int J Cardiol 117: 16-30, 2007.

AUNE E, BAEKKEVAR M, ROISLIEN J, RODEVAND O, OTTERSTAD JE: Normal reference ranges for left and right atrial volume indexes and ejection fractions obtained with real-time thee-dimensional echocardiography. Eur J Echocardiogr 10: 738-744, 2009.

AYDIN C, INCE E, KOPARAN S, CANGUL IT, NAZIROGLU M, AK F: Protective effects of long term dietary restriction on swimming exercise induced oxidative stress in the liver, heart and kidney of rat. Cell Bochem Funct 25: 129-137, 2007.

BENEK R, LEITHAUSER RM, OCHENTEL O: Blood lactate diagnostic in exercise testing and training. Int $J$ Sports Physiol Perform 6: 8-24, 2011.

BLOOMER RJ, FISHER-WELLMAN KH: Blood oxidative stress biomarkers: influence of sex, exercise training status, and dietary intake. Gend Med 5: 218-228, 2008.

BOOTH FW, LAYE MJ, SPANGENBURG EE: Gold standards for scientists who are conducting animal-based exercise studies. J Appl Physiol 108: 219-221, 2010.

BUTTAR HS, LI T, RAVI N: Prevention of Cardiovascular diseases: Role of exercise, dietary interventions, obesity and smoking cessation. Exp Clin Cardiol 10: 229-249, 2005.

CAMPBELL SE, FEBBRAIO MA: Effect of ovarian hormones on mitochondrial enzyme activity in the fat oxidation pathway of skeletal muscle. Am J Physiol Endocrinol Metab 281: 803-808, 2001. 
CARVALHO JF, MASUDA MO, POMPEU FA: Method for diagnosis and control of aerobic training in rats based on lactate threshold. Comp Biochem Physiol A Mol Integr Physiol 140: 409-413, 2005.

CASIMIRO-LOPES G, RAMOS D, SORENSON MM, SALERNO VP: Redox balance and mitochondrial glycerol phosphate dehydrogenase activity in trained rats. Eur J Appl Physiol 112: 3839-3846, 2012.

CHIRICO EN, MARTIN C, FAES C, FEASSON L, OYONO-ENGUELLE S, AUFRADET E, DUBOUCHAUD H, FRANCINA A, CANET-SOULAS E, THIRIET P, MESSONNIER L, PIALOUX V: Exercise training blunts oxidative stress in sickle cell trait carriers. J Appl Physiol 112: 1445-1453, 2012.

COLOM B, OLIVER J, ROCA P, GARCIA-PALMER FJ: Caloric restriction and gender modulate cardiac muscle mitochondrial $\mathrm{H}_{2} \mathrm{O}_{2}$ production and oxidative damage. Cardiovasc Res 74: 456-465, 2007.

CONTARTEZE RV, MANCHADO FDB, GOBATTO CA, DE MELLO MA: Stress biomarkers in rats submitted to swimming and treadmill running exercises. Comp Biochem Physiol A Mol Integr Physiol 151: 415-422, 2005.

DALEN H, THORSTENSEN A, VATTEN LJ, AASE SA, STOYLEN A: Reference values and distribution of conventional echocardiographic Doppler measures and longitudinal tissue Doppler velocities in a population free from cardiovascular disease. Circ Cardiovasc Imaging 3: 614-622, 2010.

DUNCAN GE, ANTON SD, SYDEMAN S, NEWTON RL, CORSICA JA, DURNING PE, KETTERSON TU, MARTIN AD, LIMACHER MC, PERRI MG: Prescribing exercise at varied levels of intensity and frequency A randomized trial. Arch Intern Med 165: 2362-2369, 2015.

DURSTINE JL, HASKELL WL: Effects of exercise training on plasma lipids and lipoproteins. Exerc Sport Sci Rev 22: 477-521, 1994.

ENSIGN WY, MCNAMARA DJ, FERNANDEZ ML: Exercise improves plasma lipid profiles and modifies lipoprotein composition in guinea pigs. $J$ Nutr Biochem 13: 747-753, 2012.

FERREIRA JC, ROLIM NP, BARTHOLOMEU JB, GOBATTO CA, KOKUBUN E, BRUM PC: Maximal lactate steady state in running mice: effect of exercise training. Clin Exp Pharmacol Physiol 34: 760-765, 2007.

GOBATTO CA, De MELlo MA, SIBUYA CY, De AZEVEDO JR, Dos SANTOS LA, KOKUBUN E: Maximal lactate steady state in rats submitted to swimming exercise. Comp Biochem Physiol A Mol Integr Physiol 130: 21-27, 2001.

GOLDFARB AH, MCKENZIE MJ, BLOOMER RJ: Gender comparisons of exercise-induced oxidative stress: influence of antioxidant supplementation. Appl Physiol Nutr Metab 32: 1124-1131, 2007.

GROUSSARD C, RANNOU-BEKONO F, MACHEFER G, CHEVANNE M, VINCENT S, SERGENT O, CILLARD J, GRATAS-DELAMARCHE A: Changes in blood lipid peroxidation markers and antioxidants after a single sprint anaerobic exercise. Eur J Appl Physiol 89: 14-20, 2003.

GUERREIRO LF, PEREIRA AA, MARTINS CA, WALLY C, GONÇALVES CAN: Swimming physical training in rats: Cardiovascular adaptation to exercise training protocols at different intensities. J Exerc Physiol online 18: 1-11, 2015.

HAMILTON MT, ETIENNE J, MCCLURE WC, PAVEY BS, HOLLOWAY AK: Role of local contractile activity and muscle fiber type on LPL regulation during exercise. Am J Physiol 275: E1016-E1022, 1998.

HERNANDEZ-TORRES RP, RAMOS-JIMENEZ A, TORRES-DURAN PV, ROMERO-GONZALEZ J, MASCHER D, POSADAS-ROMERO C, JUAREZ-OROPEZA MA: Effects of single sessions of low-intensity continuous and moderate-intensity intermittent exercise on blood lipids in the same endurance runners. $J$ Sci Med Sport 12: 323-331, 2009.

HUGHES RA, THORLAND WG, EYFORD T, HOOD T: The acute effects of exercise duration on serum lipoprotein metabolism. J Sports Med Phys Fitness 30: 37-44, 1990.

JACOB MH, PONTES MR, ARAUJO AS, BARP J, IRIGOYEN MC, LLESUY SF, RIBEIRO MF, BELLO-KLEIN A: Aortic-banding induces myocardial oxidative stress and changes in concentration and activity of antioxidants in male Wistar rats. Life Sci 79: 2187-2193, 2006.

JONES DP: Redefining oxidative stress. Antioxid Redox Signal 8: 1865-1879, 2006.

KACZOR JJ, HALL JE, PAYNE E, TARNOPOLSKY MA: Low intensity training decreases markers of oxidative stress in skeletal muscle of mdx mice. Free Radic Biol Med 43: 145-154, 2007. 
KRAUS WE, HOUMARD JA, DUSCHA BD, KNETZGER KJ, WHARTON MB, MCCARTNEY JS, BALES CW, HENES S, SAMSA GP, OTVOS JD, KULKARNI KR, SLENTZ CA: Effects of the amount and intensity of exercise on plasma lipoproteins. N Engl J Med 347: 1483-1492, 2002.

KUMAR CT, REDDY VK, PRASAD M, THYAGARAJU K, REDDANNA P: Dietary supplementation of vitamin E protects heart tissue from exercise-induced oxidant stress. Mol Cell Biochem 111: 109-115, 1992.

LINDQVIST P, MORNER S, HENEIN MY: Cardiac mechanisms underlying normal exercise tolerance: gender impact. Eur J Appl Physiol 112: 451-459, 2012.

LIU J, YEO HC, OVERVIK-DOUKI E, HAGEN T, DONIGER SJ, CHYU DW, BROOKS GA, AMES BN: Chronically and acutely exercised rats: biomarkers of oxidative stress and endogenous antioxidants. $J$ Appl Physiol 89: 21-28, 2002.

MANCHADO FdE B, GOBATTO CA, VOLTARELLI FA, ROSTOM DE MELLO MA: Non-exhaustive test for aerobic capacity determination in swimming rats. Appl Physiol Nutr Metab 31: 731-736, 2006.

OAKES KD, VAN DER KRAAK GJ: Utility of the TBARS assay in detecting oxidative stress in white sucker (Catostomus commersoni) populations exposed to pulp mill effluent. Aquat Toxicol 63: 447-463, 2003.

PERRINO C, GARGIULO G, PIRONTI G, FRANZONE A, SCUDIERO L, DE LAURENTIS M, MAGLIULO F, ILARDI F, CAROTENUTO G, SCHIATTARELLA GG, ESPOSITO G: Cardiovascular effects of treadmill exercise in physiological and pathological preclinical settings. Am J Physiol Heart Circ Physiol 300: H1983-H1989, 2011.

PILIS W, ZARZECZNY R, LANGFORT J, KACIUBA-USCILKO H, NAZAR K, WOJTYNA J: Anaerobic threshold in rats. Comp Biochem Physiol Comp Physiol 106: 285-289, 1993.

PINHO CA, TROMM CB, TAVARES AM, SILVA LA, SILVEIRA PC, SOUZA CT, BENETTI M, PINHO RA: Effects of different physical training protocols on ventricular oxidative stress parameters in infarction-induced rats. Life Sci 90: 553-559, 2012.

POWERS SK, QUINDRY JC, KAVAZIS AN: Exercise-induced cardioprotection against myocardial ischemiareperfusion injury. Free Radic Biol Med 44: 193-201, 2008.

RADAK Z, CHUNG HY, GOTO S: Systemic adaptation to oxidative challenge induced by regular exercise. Free Radic Biol Med 44: 153-159, 2008.

RADAK Z, KANEKO T, TAHARA S, NAKAMOTO H, OHNO H, SASVARI M, NYAKAS C, GOTO S: The effect of exercise training on oxidative damage of lipids, proteins, and DNA in rat skeletal muscle: evidence for beneficial outcomes. Free Radic Biol Med 27: 69-74, 1999.

RAMOS D, MARTINS EG, VIANA-GOMES D, CASIMIRO-LOPES G, DALERNO VP: Biomarkers of oxidative stress and tissue damage release by muscle and liver after a single bout of swimming exercise. Appl Physiol Nutr Metab 38: 507-511, 2013.

RAVI KT, SUBRAMANYAM MV, PRATHIMA S, ASHA DEVI S: Blood lipid profile and myocardial superoxide dismutase in swim-trained young and middle-aged rats: comparison between left and right ventricular adaptations to oxidative stress. J Comp Physiol B 176: 749-762, 2006.

ROPELLE ER, FLORES MB, CINTRA DE, ROCHA GZ, PAULI JR, MORARI J, DE SOUZA CT, MORAES JC, PRADA PO, GUADAGNINI D, MARIN RM, OLIVEIRA AG, AUGUSTO TM, CARVALHO HF, VELLOSO LA, SAAD MJ, CARVALHEIRA JB: IL-6 and IL-10 anti-inflammatory activity links exercise to hypothalamic insulin and leptin sensitivity through IKKbeta and ER stress inhibition. PLoS Biol 8, e1000465, 2010.

SHIOMI T, TSUTSUI H, MATSUSAKA H, MURAKAMI K, HAYASHIDANI S, IKEUCHI M, WEN J, KUBOTA T, UTSUMI H, TAKESHITA A: Overexpression of glutathione peroxidase prevents left ventricular remodeling and failure after myocardial infarction in mice. Circulation 109: 544-549, 2004.

STEFFENSEN CH, ROEPSTORFF C, MADSEN M, KIENS B: Myocellular triacylglycerol breakdown in females but not in males during exercise. Am J Physiol Endocrinol Metab 282: E634-E642, 2002.

STOREY KB: Oxidative stress: animal adaptations in nature. Braz J Med Biol Res 29: 1715-1733, 1996.

SUGAWARA J, KOMINE H, MIYAZAWA T, IMAI T, FISHER JP, OGOH S: Impact of chronic exercise training on the blood pressure response to orthostatic stimulation. J Appl Physiol 112: 1891-1896, 2012. 
THOMPSON PD: Exercise and physical activity in the prevention and treatment of atherosclerotic cardiovascular disease. Arterioscler Thromb Vasc Biol 23: 1319-1321, 2003.

TREJO-GUTIERREZ JF, FLETCHER G: Impact of exercise on blood lipids and lipoproteins. J Clin Lipidol 1: 175-181, 2007.

TUNSTALL RJ, MEHAN KA, WADLEY GD, COLLIER GR, BONEN A, HARGREAVES M, CAMERON-SMITH D: Exercise training increases lipid metabolism gene expression in human skeletal muscle. Am J Physiol Endocrinol Metab 283: 66-72, 2002.

VIJAY V, HAN T, MOLAND CL, KWEKEL JC, FUSCOE JC, DESAI VG: Sexual dimorphism in the expression of mitochondria-related genes in rat heart at different ages. PLoS One 10: 117-147, 2015.

WANG JS, LEE T, CHOW SE: Role of exercise intensities in oxidized low-density lipoprotein-mediated redox status of monocyte in men. $J$ Appl Physiol 101: 740-744, 2006.

WITTRUP HH, TYBJAERGHANSEN A, ABILDGAARD S, STEFFENSEN R, SCHNOHR P, NORDESTGAARD BG: A common substitution (Asn291Ser) in lipoprotein lipase is associated with increased risk of ischemic heart disease. J Clin Invest 99: 1606-1613, 1997.

VOLTARELLI FA, GOBATTO CA, DE MELLO MAR: Determination of anaerobic threshold in rats using the lactate minimum test. Braz J Med Biol Res 35: 1389-1394, 2002.

YANG JY, NAM JH, PARK H, CHA YS: Effects of resistance exercise and growth hormone administration at low doses on lipid metabolism in middle-aged female rats. Eur J Pharmacol 539: 99-107, 2006. 